\title{
Ocular Findings among Filipino Patients with Leprosy in a Tertiary Hospital: A Cross-sectional Survey
}

\author{
Mae N. Ramirez, MD, ${ }^{1}$ Mark Anthony D. San Juan, MD, Jay-V James G. Barit, MD, ${ }^{1}$ \\ Jacinto U. Dy-Liacco, MD² and Belen L. Dofitas, MD ${ }^{1}$ \\ ${ }^{1}$ Department of Dermatology, Philippine General Hospital, University of the Philippines Manila \\ ${ }^{2}$ Department of Ophthalmology and Visual Sciences, Philippine General Hospital, University of the Philippines Manila
}

\begin{abstract}
Background. Leprosy, a chronic granulomatous disease affecting mainly the skin and peripheral nerves, has widely recognized ocular complications. It is a significant cause of visual impairment in countries where it is still prevalent, including the Philippines.
\end{abstract}

Methods. This was a cross-sectional study that determined the clinical profile and distribution of ocular pathology among Filipino patients with leprosy seen at a tertiary institution in the Philippines.

Results. A total of 67 patients consented to be included in the study and were evaluated by an ophthalmologist. Thirty-seven out of the 67 patients diagnosed with leprosy had reported ocular findings. The average age was $41.2 \pm 13.1$ years and the majority of patients were men (78\%). Thirty-six patients were multibacillary cases, 10 (27\%) had a lepra reaction, and 24 (65\%) were undergoing multi-drug therapy. Three patients had varying degrees of visual acuity impairment (one was visually impaired with visual acuity [VA] 6/24-6/60, one with VA 3/60-5/60, and one with VA <3/60). Steroid-induced cataracts occurred in four patients $(6 \%)$ with concurrent or previous systemic corticosteroid treatment for lepra reactions. Univariate logistic regression and Fisher's exact test of patient-, disease-, and treatment-related variables on ocular morbidity revealed non-significant values for all variables except for age with an odds ratio of $1.1(95 \% \mathrm{Cl}, 1.04,1.16)(\mathrm{p}=0.001)$.

Conclusions. No ocular morbidities directly caused by leprosy were seen, and treatment-related ocular findings (steroid-induced cataracts) were the only morbidities documented. There is an age-related risk for developing ocular morbidity in patients with leprosy.

Key Words: cataract, cross-sectional studies, eye diseases, leprosy

Paper presented (Oral presentation) in the $3^{\text {rd }}$ Continental Congress of the International Society of Dermatology, October 24-27, 2012, at Durban, South Africa.

Corresponding author: Mae N. Ramirez, MD

Department of Dermatology

Philippine General Hospital

University of the Philippines Manila

Taft Avenue, Ermita, Manila 1000, Philippines

Email:mrquizon1@up.edu.ph

\section{INTRODUCTION}

Leprosy, a chronic infectious granulomatous disorder caused by Mycobacterium leprae, has widely recognized ocular complications besides its typical cutaneous and peripheral nerve involvement. ${ }^{1,2}$ Accounting for the highest incidence of ophthalmic complications for any human bacterial infection, these ocular changes may occur due to the following mechanisms: 1) direct bacterial invasion, leading to keratitis, scleritis, and uveitis; 2) trigeminal and facial nerve paralysis, resulting in lagophthalmos and exposure keratopathy; 3) lepra reactions causing iritis, corneal hypoesthesia, nerve paralysis, keratitis, etc.; and 4) destruction of autonomic fibers of the eye leading to iridocyclitis. ${ }^{3-5}$ Cataract formation, both age-related and corticosteroid-related during lepra reaction treatment, contributes to blindness in as many as $40-50 \%$ of all leprosy cases. ${ }^{6}$ The advent of multi-drug therapy (MDT) 
for leprosy has drastically reduced its global burden and its subsequent associated disabilities; however, the disease remains a significant cause of visual impairment and blindness in developing countries where it remains prevalent. ${ }^{1,6}$ In 2005, the Philippines was the largest contributor of new cases (44\%) in the Western Pacific Region at that time. ${ }^{7}$ In 2006 and 2008, the number of leprosy cases exceeded 3000 per 10,000 population. ${ }^{8}$ In 2018 , the Philippines was the sole country in the Western Pacific Region to report more than 1000 new cases. ${ }^{9}$ The country remains an endemic region with prevalence ranging from 0.3 to 0.47 from 2013 to $2018 .{ }^{9,10}$ Despite active control measures against leprosy, around $11 \%$ will have potentially sight-threatening ocular manifestations (PSOM) - cataracts, lagophthalmos, corneal hypoaesthesia, corneal ulcers, iridocyclitis/uveitis, scleritis, and glaucoma - and $2.8 \%$ will be blind. ${ }^{11,12}$

Earlier unpublished local data collected from 1977 to 1982 in Dr. Jose N. Rodriguez Memorial Hospital in Tala, Caloocan, Philippines, found blindness to occur in 232 eyes (18.2\%) of 1081 patients as a late consequence of the disease. ${ }^{13}$ Various studies on ocular leprosy published before 2009 included Filipinos in some population subsets (e.g. the Longitudinal Study of Ocular Leprosy or LOSOL study, in which one of the sites was Cebu), and have shown that lagophthalmos, cicatricial ectropion, uveitis, cataracts, corneal scars, trichiasis, and madarosis were the most common ophthalmologic complications identified. ${ }^{11,14-20}$ The majority utilized the 5-point ophthalmic evaluation to document these findings, and very few included ophthalmoscopy. Proper evaluation of ocular pathologies requires a complete ophthalmologic examination, which includes a slit-lamp examination, gonioscopy, applanation tonometry, ophthalmoscopy, and perimetry. ${ }^{21}$

Gaps in epidemiologic information for ocular leprosy remain as well, with the studies and surveys conducted being heterogeneous and with results that are difficult to generalize., ${ }^{2,11,21}$ Hence, this study aimed to provide local evidence on the burden of ocular pathologies among Filipino leprosy patients in its time using a complete ophthalmologic evaluation in a tertiary center and identified risk factors for their development.

\section{MATERIALS AND METHODS}

A cross-sectional observational prospective study was conducted at the University of the Philippines-Philippine General Hospital Section of Dermatology and Department of Ophthalmology and Visual Sciences outpatient clinics from May to October 2009. The study protocol was approved by the Institutional Review Board of the Philippine General Hospital. Using an assumed prevalence of 57\%, a confidence level of $95 \%$, and a margin of error of $7 \%$, a target sample size of 117 was computed. ${ }^{22}$

We included adult and pediatric patients clinically diagnosed with Hansen's disease and confirmed by histo- pathology who gave informed consent. The diagnosis of leprosy was defined as the presence of one or more of the following signs/symptoms of leprosy, together with skin biopsy findings compatible with leprosy: a) hypopigmented or reddish patch, plaque, or nodule with definite loss of sensation; b) peripheral nerve enlargement, pain, or tenderness; and c) acid-fast bacilli on skin lesions or nerve tissue (slit-skin smear or Fite-Faraco stain), and categorized using the WHO Classification system as either paucibacillary $(\mathrm{PB})$ or multibacillary $(\mathrm{MB})$ cases. $^{1}$

\section{Ophthalmologic Evaluation}

Volunteer patients fitting the criteria were directed to the ophthalmology department for a comprehensive eye examination, which included the following: a) directed ophthalmic history; b) gross examination of ocular adnexae (lids, eyebrows, eyelashes, conjunctivae), c) extraocular muscle testing (range of motion of six cardinal gazes); d) visual acuity without correction, then best-corrected visual acuity with manifest refraction; e) color vision test with pseudoisochromatic plates; f) applanation tonometry; g) slit-lamp examination; h) stereoscopic optic nerve and macula examination; i) indirect and dynamic gonioscopy, and $\mathrm{j}$ ) dilated indirect ophthalmoscopy. Visual acuity was measured using a Snellen chart at 6 meters reading distance. Refraction was carried out with the use of a retinoscope and phoropter, and the best-corrected visual acuity was obtained. With the best correction, color plate testing was done using an American Optical Pseudoisochromatic 18 Plate Test Book (American Optical Company, Philadelphia, USA) to assess color discrimination and optic nerve function. A slit lamp with Goldmann Applanation Tonometer (HaagStreit, United Kingdom) and digital camera attachments was used for the gross and slit-lamp examinations to visualize the anatomy of the eye. Cataractous lenses found on slitlamp evaluation were evaluated whether they were visually significant. Visually significant cataracts in this study were defined as the presence of any of the following, in either eye: best-corrected vision less than 6/12 in the cataractous eye, any Lens Opacities Classification System III grading of $\geq 2$, the primary cause of visual impairment in the said eye, and reported general vision was poor/very poor. ${ }^{23}$ A Volk Super Field fundus lens (Volk Optical, Ohio, USA) was used for stereoscopic optic nerve and macula examination through an undilated pupil. Indirect and dynamic gonioscopy was performed under topical anesthesia (proparacaine 0.5\% eye drops) using an Ocular Sussmann Four-Mirror Gonioscope (Ocular Instruments Inc., Washington, USA) to visualize the status of the angles. For patients assessed to have infectious eye lesions, gonioscopy was deferred and tonometry measurements were obtained with a non-contact air-puff tonometer. Dilation of the patient's pupils was done with one drop of phenylephrine-tropicamide $0.5 \%$ ophthalmic drops, followed by indirect ophthalmoscopy to visualize the entire retina. 


\section{Data Analysis}

Analysis was done by patient rather than by eye. Descriptive statistics were employed for continuous variables (age, duration of treatment), presented as means and standard deviations; number and proportion for categorical variables, describing the distribution of ocular pathologies as well as sociodemographic, disease, and treatment characteristics. Fisher's exact test was used to analyze the association of visually significant cataracts with polar lepromatous leprosy and erythema nodosum leprosum (ENL) or Type II lepra reaction. Results for univariate analysis of selected variables were expressed as odds ratios and $p$ values. Analysis was done using STATA Version 11.

\section{RESULTS}

Eighty-seven diagnosed cases of leprosy volunteered for the study, and 67 (77\%) underwent ophthalmologic evaluation. Twenty patients consented to the study but did not proceed to the ophthalmology department as instructed, and were not counted as evaluable participants. Thirty-seven of the 67 patients examined in toto (55.2\%) had ocular findings.

Demographics and the clinical profile of these patients with ocular morbidity are summarized in Table 1 . Among the 37 who had ocular findings, 28 were male (75.7\%) and 9 were female (24.3\%). The mean age was $41.2 \pm 13.1$ years (ranging from $7-61$ years). Co-morbidities were present in 13 patients (35.1\%), with the most common co-morbidity being Cushing syndrome $(n=3,8.1 \%)$ secondary to oral corticosteroid intake for ENL, followed by hypertension, tuberculosis, and dermatophyte infection. $\mathrm{PB}$ and $\mathrm{MB}$ leprosy patients comprised 2.7\% (1 patient) and 97.3\% (36 patients), respectively. Ten patients (27.0\%) also had lepra reactions, and of those with ocular involvement, 4 (5.97\%) had type I lepra reactions and 6 (8.9\%) had type II reactions. The majority of included patients $(24,64.9 \%)$ were undergoing treatment at the time of evaluation; $5(13.5 \%)$ were released from treatment within 1 year; 7 (18.9\%) released from treatment for more than a year; and 1 was a newly diagnosed patient $(2.7 \%)$ who had not received the first dose of MDT. All participants with ocular morbidity were classified as multibacillary leprosy, including 1 newly diagnosed case and 36 (97.3\%) who have received MB-MDT treatment. The other remaining patient received dapsone monotherapy in the late 1990s. Univariate logistic regression analysis of patient-, disease-, and treatment-related variables showed that age was the only significant variable (Prevalence odds ratio $1.10,95 \%$ CI 1.04,1.16).

The following potentially sight-threatening ocular manifestations were not found in the sample population: corneal anesthesia, lagophthalmos, uveitis, scleritis, and advanced glaucoma.

Sixty-three patients or $94.0 \%$ had a VA of $6 / 6$ in both eyes whether uncorrected $(n=30)$ or with spectacles $(n=33)$. The remaining four patients had less than $6 / 6$ vision in either eye. There were two patients with visually significant steroid-

Table 1. Clinical and demographic factors and ocular morbidity

\begin{tabular}{|c|c|c|c|c|}
\hline & $\begin{array}{c}\text { With Ocular } \\
\text { Morbidity ( } N=37)\end{array}$ & $\begin{array}{l}\text { Without Ocular } \\
\text { Morbidity }(\mathbf{N}=30)\end{array}$ & Odds Ratio (95\% Cl) & PValue \\
\hline \multicolumn{5}{|l|}{ Patient-related factors } \\
\hline \multicolumn{5}{|l|}{ Gender } \\
\hline Male & $2876)$ & $24(80)$ & - & - \\
\hline Female & $9(24)$ & $6(20)$ & $1.29(0.40,4.13)$ & 0.673 \\
\hline Age (years) & $41.2 \pm 13.1$ & $30.3 \pm 7.16$ & $1.10(1.04,1.16)$ & 0.001 \\
\hline Comorbidities & $13(35)$ & $9(30)$ & $1.26(0.45,3.55)$ & 0.657 \\
\hline \multicolumn{5}{|l|}{ Leprosy-related factors } \\
\hline \multicolumn{5}{|l|}{ Disease classification } \\
\hline PB & 1 (3) & $0(0)$ & - & - \\
\hline MB & $36(97)$ & $30(100)$ & $2.5(0.22,29.82)$ & 0.450 \\
\hline Lepra Reaction & $10(27)$ & $10(33)$ & $0.74(0.26,2.12)$ & 0.575 \\
\hline Type I & $4(11)$ & $2(7)$ & & \\
\hline Type II/ENL & $6(16)$ & $8(27)$ & & \\
\hline \multicolumn{5}{|l|}{ Treatment-related factors } \\
\hline \multicolumn{5}{|l|}{ Treatment status } \\
\hline New & 1 (3) & $2(7)$ & - & - \\
\hline Ongoing & $24(65)$ & $24(80)$ & $2(0.17,23.56)$ & 0.582 \\
\hline RFT $<1 \mathrm{yr}$ & $5(14)$ & $1(3)$ & $10(0.40,250.40)$ & 0.161 \\
\hline RFT $>1 \mathrm{yr}$ & 7 (19) & $3(10)$ & $4.67(0.30,73.38)$ & 0.273 \\
\hline Duration of treatment (months) & $15.6 \pm 10.8$ & $13.2 \pm 8.53$ & $1.03(0.97,1.08)$ & 0.336 \\
\hline Delay in treatment (months) & $18.6 \pm 24.6$ & $23 \pm 21.45$ & $0.99(0.97,1.01)$ & 0.443 \\
\hline \multicolumn{5}{|l|}{ Type of treatment } \\
\hline PB-MDT & $0(0)$ & $0(0)$ & $1.00^{*}$ & \\
\hline MB-MDT & $36(97)$ & $30(100)$ & & \\
\hline Alternative regimen & $1(3)$ & $0(0)$ & & \\
\hline
\end{tabular}

PB, Paucibacillary; MB, Multibacillary; ENL, Erythema nodosum leprosum; RFT, Released from treatment *Fisher's exact test used 
induced cataracts (one patient with bilateral best corrected vision at 5/60 and the other at 6/24). The remaining two patients with decreased VA were incidentally found to have diseases completely unrelated to ocular leprosy (1 case of Stargardt disease having 2/60 best-corrected vision in both eyes, and 1 case of rhegmatogenous retinal detachment having $1 / 60$ best-corrected vision in one eye and $6 / 6$ on the other). The frequency of distance visual impairment in the study population, grouped by treatment category, is shown in Table 2.

The most common abnormal ocular finding in the study was an error of refraction involving 23 patients (Table 3). The next most common pathologic finding was cataracts, found in 7 patients. Four patients (6.0\%) were found to have steroidinduced cataracts secondary to oral prednisone therapy for ENL, two of whom had concomitant Cushing syndrome. These patients were all men aged 17, 25, 29, and 45 years. Three other patients have undergone cataract surgery with
$6 / 6$ post-operative vision in both eyes. Seven other patients had other diagnoses that existed before the diagnosis of leprosy. The presence of cataracts was not significantly associated with polar lepromatous leprosy $(\mathrm{p}=1.0)$ and erythema nodosum leprosum $(\mathrm{p}=0.54)$.

\section{DISCUSSION}

The prevalence of ocular involvement from leprosy ranges from 6-100\%, varying greatly depending on the study population, method, and clinical profiles. ${ }^{24}$ The observed ocular complications in this study were quite low (only $6 \%$ for steroid-induced cataracts), and no leprosy-specific findings were detected. In general, the low prevalence of vision loss in patients with leprosy is likely a result of effective MDT and surveillance programs. ${ }^{21}$ Race may play a role, though it may be unclear; for example, in the LOSOL study, more eye disease was documented in the

Table 2. Frequency of distance visual impairment $(\mathrm{N}=67)$

\begin{tabular}{|c|c|c|c|c|c|}
\hline \multirow[b]{2}{*}{$\begin{array}{l}\text { Treatment } \\
\text { Category }\end{array}$} & \multirow[b]{2}{*}{$\begin{array}{l}\text { No Visual } \\
\text { Impairment } \\
\text { N (\%) }\end{array}$} & \multicolumn{4}{|c|}{ Visual Impairment } \\
\hline & & $\begin{array}{c}\text { Mild } \\
\text { (VA 6/12 to 6/18) } \\
n(\%)\end{array}$ & $\begin{array}{c}\text { Moderate } \\
\text { (VA 6/18 to 6/60) } \\
n(\%)\end{array}$ & $\begin{array}{c}\text { Severe } \\
\text { (VA 6/60 to 3/6) } \\
\text { n (\%) }\end{array}$ & $\begin{array}{c}\text { Blindness } \\
(\mathrm{VA}<3 / 60) \\
n(\%)\end{array}$ \\
\hline New & $3(4.5)$ & $0(0)$ & $0(0)$ & $0(0)$ & $0(0)$ \\
\hline Ongoing MDT & $46(68.7)$ & $0(0)$ & $1(1.5)$ & $1(1.5)$ & $0(0)$ \\
\hline$R F T<1$ yr. & $6(9.0)$ & $0(0)$ & $0(0)$ & $0(0)$ & $0(0)$ \\
\hline$R F T>1 \mathrm{yr}$. & 9 (13.4) & $0(0)$ & $0(0)$ & $0(0)$ & $1(1.5)$ \\
\hline
\end{tabular}

VA, visual acuity; MDT, Multidrug treatment; RFT, Released from treatment

Table 3. Ocular findings of the study population $(\mathrm{N}=67)$

\begin{tabular}{|c|c|c|}
\hline Ocular Findings & No. (\%) & Comments \\
\hline Normal ophthalmologic findings & $30(45)$ & \\
\hline Error of refraction & $23(34)$ & \\
\hline Presbyopia & $14(61)$ & \\
\hline Myopia & $4(17)$ & \\
\hline Hyperopia & $3(13)$ & \\
\hline Astigmatism & $2(9)$ & \\
\hline \multicolumn{3}{|l|}{ Lens pathology } \\
\hline Steroid-induced Cataract & $4(6)$ & 2 out of 4 patients had Cushing syndrome \\
\hline Pseudophakia for presenile cataracts & $2(3)$ & Underwent cataract surgery before the study, VA 6/6 OU \\
\hline Pseudophakia for steroid-induced cataracts & $1(2)$ & Underwent cataract surgery before the study, VA 6/6 OU \\
\hline \multicolumn{3}{|l|}{ Iris pathology } \\
\hline Posterior synechiae & $1(2)$ & $\begin{array}{l}\text { 7/F with G6PD deficiency, suggestive of a previous old anterior } \\
\text { uveitis prior to leprosy diagnosis, VA } 6 / 6\end{array}$ \\
\hline \multicolumn{3}{|l|}{ Corneal/Conjunctival pathology } \\
\hline Pterygium & $1(2)$ & $39 / \mathrm{M}$ with small pterygium for both eyes, not requiring surgery \\
\hline Dry Eye & $1(2)$ & 43/M treated for dry eye even before diagnosis of leprosy \\
\hline \multicolumn{3}{|l|}{ Optic nerve pathology } \\
\hline Glaucoma Suspect & $1(2)$ & $\begin{array}{l}\text { 61/M with bilateral symmetric enlarged cup-to-disc ratios; } \\
\text { subsequent workup normal }\end{array}$ \\
\hline \multicolumn{3}{|l|}{ Retinal pathology } \\
\hline Chorioretinal Scar & $1(2 \%)$ & $60 / \mathrm{M}$, incidental finding \\
\hline Rhegmatogenous Retinal Detachment & $1(2 \%)$ & 44/M, longstanding finding \\
\hline Stargardt Disease & $1(2 \%)$ & 40/F, poor VA since childhood \\
\hline
\end{tabular}

VA, visual acuity; G6PD, glucose-6-phosphate dehydrogenase 
Indian and Ethiopian study participants compared to their Filipino counterparts. ${ }^{11}$

In this study, analysis of patient-, disease-, and treatment-related variables did not demonstrate any significant associations except for age (increased risk for ocular morbidity by $10 \%$ for every one-year increase in age) associated with increased ocular morbidity. In general, literature is conflicting on associations with risk factors. A study of 292 patients with MB leprosy followed over 2 years while on MDT did not show any significant risk factor associations with age, sex, leprosy classification, duration of disease, reactional state, or smear indices, but was significantly associated with Grade 2 disability of all extremities. ${ }^{25}$ In a study examining 386 patients with MB leprosy, a significant association for PSOMs was found in patients presenting with symptoms (e.g., pain, erythema, inability to close the eye, burning, and irritation) (OR 2.9, 1.34-6.26). ${ }^{21}$ In 69 patients in Nigeria, there was no statistically significant difference in the incidence of ophthalmic lesions between sexes and leprosy classification. ${ }^{26}$ In 202 Filipino patients with $\mathrm{MB}$ leprosy who were monitored for at least five years, ocular abnormalities included corneal hypoaesthesia before treatment (6\%) and lagophthalmos was $3.4 \% .{ }^{27}$ In 302 patients with leprosy in India, ocular disability occurred in $39.4 \%$, with $13.07 \%$ having grade 1 disability (eye problems due to leprosy present but vision not impaired), and $19.86 \%$ having grade 2 disability (severe visual impairment with $V A<6 / 60$ or inability to count fingers at 6 meters). ${ }^{28}$ The visual impairments were more common in those with disease duration longer than one year and in those staying in leprosaria. ${ }^{29}$ In a study in Brazil, a greater than 6 times chance of intense adnexal involvement was seen in patients over the age of 50 years, mainly due to Meibomian gland dysfunction. ${ }^{24}$

The most common ocular morbidity detected was error of refraction, with most having good visual acuity. This likely mirrors the general population, wherein refractive errors are the most common cause of visual impairment. ${ }^{29}$

The second most common finding in the study was cataracts. Various studies on ocular leprosy document cataracts as one of the leading causes of blindness in leprosy patients (40-50\% of all leprosy cases, or $86.7 \%$ of analyzed patients), but their development is likely due to advancing age. ${ }^{5,14,30,31}$ It has been found to develop at around $7 \%$ per year in patients with lepromatous leprosy over 40 years of age. ${ }^{25}$ The influence of the disease on cataract formation is unclear, ${ }^{3,5}$ but the presence of leprosy triples the risk of cataract formation. ${ }^{24}$ Early hypotheses include infiltration of the iris by the mycobacteria and production of quinones, promoting cataractogenesis., ${ }^{3,32}$ Inflammation has been purported as a cause upon histological examination of cataracts. ${ }^{5}$ The role of chronic uveitis in cataract formation is unclear. ${ }^{6}$ Cataract formation in leprosy patients may also be due to chronic oral corticosteroid use in severe or recurrent lepra reactions, ${ }^{6}$ as observed in four patients in this study.
Lepra reactions, on their own, may contribute, with ENL increasing the risk by around 6 times. ${ }^{21}$

The cases of severe visual impairment documented in this study were not related to leprosy. Stargardt disease, an inherited macular dystrophy caused by mutations in the $\mathrm{ABCA} 4$ gene encoding a retinal transporter protein, is the most prevalent form of macular degeneration in children. Patients with Stargardt disease develop severe vision loss within their first or second decades of life, which progresses to irreversible decreased visual acuity in almost all cases. Presently, there are no standard treatments for Stargardt disease. ${ }^{33}$ Rhegmatogenous retinal detachment, on the other hand, refers to a separation of the neurosensory retina from the retinal pigment epithelium caused by the entry of fluid into the subretinal space through a full-thickness defect. ${ }^{34}$

The study has several limitations, mainly not having achieved the target sample size, which likely affected the significance of the variables being examined and reflected the lack of precision of the obtained estimates. As the study is only a single-point ophthalmologic examination, the development of other long-term complications cannot be observed, in contrast to longitudinal studies with a long-term follow-up period. There are multiple rare ocular pathologies recorded that are unrelated to leprosy, which can be attributed to chance and the fact that the study was conducted in a tertiary end-referral center in the country.

\section{CONCLUSION}

In this small subset of patients with leprosy examined in a single institution, no ocular morbidities directly caused by leprosy were seen, and treatment-related ocular findings (steroid-induced cataracts) were the only morbidities documented. There is an age-related risk for developing ocular morbidity in patients with leprosy. We recommend a larger sample population, ideally a multicenter study involving referral institutions catering to patients with leprosy, and a longer follow-up period to detect long-term ocular complications.

\section{Acknowledgments}

The authors would like to thank Mr. Mark Javelosa and Dr. Patrick S. Quezon for their contributions and insights to data analysis and additional review of this manuscript.

\section{Statement of Authorship}

All authors participated in the data collection and analysis and approved the final version submitted.

\section{Author Disclosure}

All authors declared no conflicts of interest.

\section{Funding Source}

This study was funded by the authors. No external funding agency. 


\section{REFERENCES}

1. World Health Organization. WHO Expert Committee on Leprosy. World Health Organ Tech Rep Ser. 2012; (968):1-61, 1 p following 61. https://apps.who.int/iris/handle/10665/75151

2. Ffytche TJ. The continuing challenge of ocular leprosy. $\mathrm{Br} \mathrm{J}$ Ophthalmol. 1991 Feb; 75(2):123-4. doi: 10.1136/bjo.75.2.123.

3. Ffytche TJ. Role of iris changes as a cause of blindness in lepromatous leprosy. Br J Ophthalmol. 1981 Apr; 65(4):231-9. doi: 10.1136/bjo.65.4.231.

4. Espiritu CG, Gelber R, Ostler HB. Chronic anterior uveitis in leprosy: an insidious cause of blindness. Br J Ophthalmol. 1991 May; 75(5):273-5. doi: 10.1136/bjo.75.5.273.

5. Grzybowski A, Nita M, Virmond M. Ocular leprosy. Clin Dermatol. 2015 Jan-Feb; 33(1):79-89. doi: 10.1016/j.clindermatol.2014.07.003.

6. Hogeweg, $\mathrm{M}$ et al. Prevention of blindness in leprosy and the role of the Vision 2020 Programme. Eye 2005: 19, 1099-1105.

7. World Health Organization - Regional Office for the Western Pacific. Epidemiological review of leprosy in the WHO Western Pacific Region [Internet]. 2007. [cited $2021 \mathrm{Mar}$ ]. Available from: http://iris. wpro.who.int/handle/10665.1/10492

8. Handog EB, Gabriel MT, Co CC. Leprosy in the Philippines: a review. Int J Dermatol. 2011 May; 50(5):573-81. doi: 10.1111/j.13654632.2011.05044.x.

9. World Health Organization. Epidemiological review of leprosy in the Western Pacific Region: 1983-2018 [Internet]. 2020. [cited 2021 Mar]. Available from: http://iris.wpro.who.int/handle/10665.1/14710

10. Department of Health. National leprosy control program [Internet]. 2018. [cited $2021 \mathrm{Mar}$. Available from: https://doh.gov.ph/leprosycontrol-program

11. Courtright P, Daniel E, Sundarrao, Ravanes J, Mengistu F, Belachew $\mathrm{M}$, et al. Eye disease in multibacillary leprosy patients at the time of their leprosy diagnosis: findings from the Longitudinal Study of Ocular Leprosy (LOSOL) in India, the Philippines and Ethiopia. Lepr Rev. 2002 Sep; 73(3):225-38.

12. Bairappagari MEJ, Thompson KJ, Daniel E. The eye in leprosy. In: Scollard DM and Gillis TP, eds. International textbook of leprosy [Internet]. 2016. [cited 2021 Jan]. Available from: https:// internationaltextbookofleprosy.org/chapter/eye-leprosy?sect=chapter

13. Lim, GD. Ocular Manifestations of Hansen's Disease Among Leprosy Patients in the Dr. Jose N. Rodriguez Memorial Hospital, Tala, Caloocan. 1997-1982 (unpublished).

14. Mpyet C, Solomon AW. Prevalence and causes of blindness and low vision in leprosy villages of north eastern Nigeria. $\mathrm{Br} \mathrm{J}$ Ophthalmol. 2005 Apr;89(4):417-9. doi: 10.1136/bjo.2004.048777. Erratum in: Br J Ophthalmol. 2005 Jun; 89(6):787.

15. Mvogo CE, Bella-Hiag AL, Ellong A, Achu JH, Nkeng PF. Ocular complications of leprosy in Cameroon. Acta Ophthalmol Scand. 2001 Feb; 79(1):31-3. doi: 10.1034/j.1600-0420.2001.079001031.x.

16. Waddell KM, Saunderson PR. Is leprosy blindness avoidable? The effect of disease type, duration, and treatment on eye damage from leprosy in Uganda. Br J Ophthalmol. 1995 Mar; 79(3):250-6. doi: 10.1136/bjo.79.3.250.

17. Daniel E, Koshy S, Rao GS, Rao PS. Ocular complications in newly diagnosed borderline lepromatous and lepromatous leprosy patients: baseline profile of the Indian cohort. Br J Ophthalmol. 2002 Dec; 86(12):1336-40. doi: 10.1136/bjo.86.12.1336.

18. Lewallen S, Tungpakorn NC, Kim SH, Courtright P. Progression of eye disease in "cured" leprosy patients: implications for understanding the pathophysiology of ocular disease and for addressing eyecare needs. Br J Ophthalmol. 2000 Aug; 84(8):817-21. doi: 10.1136/bjo.84.8.817.
19. Cakiner T, Karaçorlu MA. Ophthalmic findings of newly diagnosed leprosy patients in Istanbul Leprosy Hospital, Turkey. Acta Ophthalmol Scand. 1998 Feb; 76(1):100-2. doi: 10.1034/j.16000420.1998.760119.x.

20. Nepal BP, Shrestha UD. Ocular findings in leprosy patients in Nepal in the era of multidrug therapy. Am J Ophthalmol. 2004 May; 137(5):888-92. doi: 10.1016/j.ajo.2003.12.048.

21. Parikh R, Thomas S,MuliyilJ,Parikh S, Thomas R. Ocular manifestation in treated multibacillary Hansen's disease. Ophthalmology. 2009 Nov; 116(11):2051-7.e1. doi: 10.1016/j.ophtha.2009.04.021.2009 Sep 19.

22. Pourhoseingholi MA, Vahedi M, Rahimzadeh M. Sample size calculation in medical studies. Gastroenterol Hepatol Bed Bench. 2013 Winter; 6(1):14-7. PMID: 24834239; PMC4017493.

23. Richter GM, Chung J, Azen SP, Varma R; Los Angeles Latino Eye Study Group. Prevalence of visually significant cataract and factors associated with unmet need for cataract surgery: Los Angeles Latino Eye Study. Ophthalmology. 2009 Dec;116(12):2327-35. doi: 10.1016/ j.ophtha.2009.05.040.2009 Oct 7.

24. Pavezzi PD, do Prado RB, Boin Filho PÂ, Gon AdS, Tuma B, et al. (2020) Evaluation of ocular involvement in patients with Hansen's disease. PLOS Neglected Tropical Diseases 14(9): e0008585. https://doi.org/10.1371/journal.pntd.0008585

25. Daniel E, Sundar Rao PS. Evolution of vision reducing cataract in skin smear positive lepromatous patients: does it have an inflammatory basis? Br J Ophthalmol. 2007 Aug; 91(8):1011-3. doi: 10.1136/ bjo.2006.112953.

26. Ebeigbe JA, Kio F. Ocular leprosy in institutionalized Nigerian patients. Ghana Med J. 2011 Jun; 45(2):50-3. doi: 10.4314/gmj.v45i2.68928.

27. Ravanes JM, Cellona RV, Balagon M, Abalos RM, Walsh GP, Walsh DS. Longitudinal ocular survey of 202 Filipino patients with multibacillary (MB) leprosy treated with 2 year WHO-multiple drug therapy. Southeast Asian J Trop Med Public Health. 2011 Mar; 42(2):323-30.

28. Singh L, Malhotra R, Bundela RK, Garg P, Dhillon KS, Chawla S, Lal BB. Ocular disability--WHO grade 2 in persons affected with leprosy. Indian J Lepr. 2014 Jan-Mar; 86(1):1-6.

29. Pascolini D, Mariotti SP. Global estimates of visual impairment: 2010. Br J Ophthalmol. 2012 May;96(5):614-8. doi: 10.1136/ bjophthalmol-2011-300539.

30. Samanta SK, Das D. Recent advances in ocular leprosy. Indian J Lepr. 2007 Apr-Sep; 79(2-3):135-50.

31. Eballé AO, Owono D, Book AU, Bella AL, Mvogo CE, Mba N. Prevalence and etiologies of visual handicaps in leprosy patients in the south of Cameroon. Clin Ophthalmol. 2009; 3:195-8. doi: 10.2147/ opth.s4495.

32. Prabhakaran K. Cataract in leprosy: a biochemical approach. Lepr Rev. 1971 Mar; 42(1):11-3. doi: 10.5935/0305-7518.19710002.

33. Lu LJ, Liu J, Adelman RA. Novel therapeutics for Stargardt disease. Graefes Arch Clin Exp Ophthalmol. 2017 Jun;255(6):1057-1062. doi: 10.1007/s00417-017-3619-8.

34. Sultan ZN, Agorogiannis EI, Iannetta D, Steel D, Sandinha T. Rhegmatogenous retinal detachment: a review of current practice in diagnosis and management. BMJ Open Ophthalmol. 2020 Oct 9;5(1):e000474. doi: 10.1136/bmjophth-2020-000474. Erratum in: BMJ Open Ophthalmol. 2021 Mar 14; 6(1):e000474corr1. 